\title{
Pengetahuan Ibu Hamil Trimester III Tentang KB Pasca Persalinan di Puskesmas Jetis Kota, Yogyakarta
}

\author{
Nining Kurnia ${ }^{1}$, Yhona Paratmanitya ${ }^{2}$, Oktaviana Maharani ${ }^{3}$ \\ 1,2,3 Sekolah Tinggi Ilmu Kesehatan Alma Ata Yogyakarta \\ Jalan Ringroad Barat Daya No 1 Tamantirto, Kasihan, Bantul, Yogyakarta
}

\begin{abstract}
Abstrak
Jumlah penduduk Indonesia semakin tahun semakin meningkat. Untuk menekan laju pertumbuhan penduduk pemerintah mencanangkan progran keluarga berencana pasca persalinan. Di Kota Yogyakarta yang menggunakan KB pasca persalinan sebanyak 527 sedangkan di Puskesmas Jetis Kota Yogyakarta 167 dari 363 sasaran ibu hamil. Sukses atau tidaknya program keluarga berencana dipengaruhi oleh pengetahuan dan pendidikan. Tujuan penelitian untuk mengetahui gambaran tingkat pengetahuan ibu hamil trimester III tentang KB pasca persalinan di Puskesmas Jetis Kota Yogyakarta. Jenis penelitian ini deskriptif kuantitatif dengan pendekatan cross sectional. Sampel diambil dengan teknik sampling jenuh yang berjumlah 45 orang ibu hamil trimester III. Analisis data menggunakan analisis univariat. Hasil penelitian menunjukan sebagian besar ibu hamil trimester III berusia 20-35 tahun (77,7\%), berpendidikan SMA (37,8\%), tingkat pengetahuan ibu hamil sebagian besar berpengetahuan cukup (51,1\%). Sebagian besar berencana menggunakan KB suntik setelah melahirkan (44,4\%). Kesimpulan tingkat pengetahuan ibu hamil trimester III tentang KB pasca persalinan sebagian besar berpengetahuan cukup.
\end{abstract}

Kata Kunci: pengetahuan, KB pasca persalinan

\section{The Knowledge Level of Pregnant Women in Trimester III about Family Planning Post Delivery at Puskesmas Jetis Kota, Yogyakarta}

\begin{abstract}
The population of Indonesia increased every year. The goverment makes family planning post delivery to press off Indonesian growth. In Yogyakarta family planning post delivery were used by 527 people, at Puskesmas Jetis were 167 women from 363 total target of pregnant women. A succession of this program influenced by knowledge and education. The purpose of this study was to know the knowledge level of pregnant women in trimester III about family planning post delivery at Puskesmas Jetis Yogyakarta. The methode of this study was descriptive quantitative with cross sectional design. The sample obtained by saturated sampling technique which consisted of 45 pregnant women trimester III. The data used univariate analysys. The results showed that most of pregnants women in trimester III was aged 20-35 years (77.7\%), high school education (37.8\%), and there was $51.1 \%$ of pregnant women in fair knowledge level. Most of pregnant women decides to used family planning injection post delivery (44.4\%). In conclusion, the knowledge level of pregnant women in trimester III about family planning post delivery was mostly in fair knowledge level.
\end{abstract}

Keywords: the knowledge level, family planning post delivery

Info Artikel:

Artikel dikirim pada 28 Januari 2014

Artikel diterima pada 28 Januari 2014 


\section{PENDAHULUAN}

Laju pertumbuhan penduduk ditentukan oleh tingkat kelahiran dan tingkat kematian. Tingkat kelahiran kasar dan tingkat kematian kasar masingmasing menunjukkan jumlah kelahiran hidup dan jumlah kematian per 1.000 penduduk per tahun(1). Laju pertumbuhan penduduk di Indonesia meningkat dengan cukup pesat. Badan Pusat Statistik (BPS) mengumumkan jumlah penduduk Indonesia tahun 2013 terdapat sejumlah 244,2 juta jiwa dalam rangka upaya pengendalian jumlah penduduk, pemerintah menerapkan program Keluarga Berencana (KB).

Keputusan untuk menunda kehamilan dapat dilakukan dengan menggunakan metode kontrasepsi setelah persalinan(2). Berdasarkan dari hasil pemantauan Dinas Kesehatan Kota Yogyakarta (DINKES Kota Yogyakarta) tahun 2013, pelayanan Keluarga Berencana (KB) pasca persalinan di DIY tahun 2013 sebanyak 2213 peserta KB pasca persalinan , di kota Yogyakarta sebanyak 527 peserta KB pasca persalinan, sedangkan di Puskesmas Jetis Kota Yogyakarta sebanyak 167 peserta KB pasca salin yang menggunakan IUD dari 363 sasaran ibu hamil tahun 2013(3). KB pasca salin merupakan inisiasi pemakaian metode kontrasepsi dalam waktu enam minggu pertama setelah persalinan. Keunggulan KB pasca persalinan yaitu dapat dipasang segera setelah melahirkan atau keguguran, tidak menyakiti ibu dua kali, efektifitas tinggi, tidak mengganggu produksi ASI, tidak mengganggu hubungan seksual. Jenis-jenis KB pasca salin yaitu IUD, implan dan suntik(4).

Berdasarkan studi pendahuluan tanggal 12 November 2014 di Puskesmas Jetis Kota Yogyakarta, peneliti melakukan wawancara kepada 10 ibu hamil hanya 2 orang yang bisa menjawab mengenai KB pasca persalinan. Melalui studi pendahuluan yang telah peneliti lakukan dapat disimpulkan secara umum responden memiliki pengetahuan dalam kategori kurang tentang program KB pasca salin. Hal ini tentu akan berdampak pada pemilihan alat kontrasepsi ibu setelah persalinan nanti(5).

Pendidikan akan menghasilkan banyak perubahan seperti pengetahuan, sikap dan perbuatan. Tingkat pengetahuan ibu sangat mempengaruhi cara pemilihan KB pasca melahirkan, semakin tinggi pendidikannya maka semakin luas pengetahuannya(6). Cara mengukur tingkat pengetahuan dapat dilakukan dengan wawancara dan angket yang menanyakan suatu materi yang diukur dari subyek penelitian(7). Berdasarkan latar belakang, peneliti tertarik meneliti Gambaran Tingkat Pengetahuan Ibu Hamil Trimester III Tentang KB Pasca Persalinan di Puskesmas Jetis Kota Yogyakarta. Penelitian ini bertujuan untuk mengetahui Gambaran Tingkat Pengetahuan Ibu
Hamil TM III Tentang KB Pasca Persalinan yang meliputi karakteristik, tingkat pengetahuan dan rencaya KB yang akan digunakan setelah melahirkan di Puskesmas Jetis Kota Yogyakarta.

\section{BAHAN DAN METODE}

Jenis penelitian ini adalah deskriptif kuantitatif8 dengan pendekatan cross sectional. Penelitian ini dilakukan di Puskesmas Jetis Kota, Yogyakarta. Pengambilan sampel menggunakan teknik total sampling yang berjumlah 45 Ibu hamil Trimester III yang melakukan ANC di Puskesmas Jetis Kota Yogyakarta. Data diambil menggunakan kuesioner yang dibuat sendiri oleh peneliti dan sudah dilakukan uji validitas dan reliabilitas. Validitas diukur dengan tingkat segnifikansi $5 \%$ menggunakan rumus pearson product moment jika harga $r_{\text {hitung }}$ lebih besar atau sama dengan $r_{\text {tabel }}$ maka dinyatakan butir soal tersebut valid. Untuk menguji reliabilitas dilakukan dengan uji Split Half, hasilnya nilai Guttman Split Half 0,756 lebih besar dari $r_{\text {tabel }} 0,413$ maka kuesioner dinyatakan reliabel. Variabel dalam penelitian ini adalah variabel tunggal yaitu tingkat pengetahuan ibu hamil Trimester III di Puskesmas Jetis Kota Yogyakarta.

\section{HASIL DAN BAHASAN}

Karakteristik responden dapat dilihat pada Tabel 1 yang menunjukan bahwa ibu hamil trimester III di Puskesmas Jetis Kota Yogyakarta mayoritas berumur 20-35 tahun sebanyak 35 orang atau $77,7 \%$. Pendidikan ibu mayoritas $31,1 \%$ atau 14 orang lulusan SMA. Dilihat dari tabel bahwa Paritas ibu hamil trimester III mayoritas multipara sebanyak $57,7 \%$ atau 26 orang.

Tabel 1. Distribusi Frekuensi Karakteristik Ibu Hamil di Puskesmas Jetis Kota Yogyakarta tahun 2015

\begin{tabular}{lcc}
\hline Karakteristik Ibu & f & \% \\
\hline Umur Ibu & & \\
<20 Tahun & 0 & 0 \\
20-35 Tahun & 35 & 77,7 \\
>35 Tahun & 10 & 22,2 \\
Pendidikan Ibu & & \\
$\quad$ Tidak Sekolah & 2 & 4,4 \\
Tamat SD & 10 & 22,2 \\
Tamat SMP & 7 & 15,6 \\
Tamat SMA & 14 & 31,1 \\
Perguruan Tinggi & 12 & 26,7 \\
Paritas & & \\
Primipara & 19 & 42,2 \\
Multipara & 26 & 57,8 \\
$\quad$ Grandemultipara & 0 & 0 \\
Total & 45 & 100 \\
\hline
\end{tabular}

Sumber: Data Primer Tahun 2015 
Berdasarkan Tabel 2 dapat diketahui bahwa ibu hamil trimester III di Puskesmas Jetis Kota Yogyakarta sebelum hamil mayoritas $42,2 \%$ atau 19 orang menggunakan KB suntik dan minoritas 2,2\% atau 1 orang menggunakan KB IUD.

Tabel 2. Distribusi Frekuensi Jenis Alat Kontrasepsi Yang Digunakan Ibu Hamil Trimester III Sebelum Hamil di Puskesmas Jetis Kota Yogyakarta

\begin{tabular}{lcc}
\hline Jenis KB Sebelum Hamil & f & \% \\
\hline Suntik & 19 & 42,2 \\
IUD & 1 & 2,2 \\
Susuk & 7 & 15,6 \\
Tidak KB & 18 & 40 \\
Jumlah & 45 & 100 \\
\hline
\end{tabular}

Sumber: Data Primer Tahun 2015

Tabel 3. Distribusi Frekuensi Jenis Alat Kontrasepsi Yang Digunakan Ibu Hamil Trimester III setelah melahirkan di Puskesmas Jetis Kota Yogyakarta

\begin{tabular}{lcc}
\hline $\begin{array}{c}\text { Jenis KB yang Akan } \\
\text { Digunakan Setelah Melahirkan }\end{array}$ & $\mathbf{f}$ & $\%$ \\
\hline Suntik & 20 & 44,4 \\
IUD & 15 & 33,3 \\
Susuk & 10 & 22,2 \\
Jumlah & 45 & 100 \\
\hline
\end{tabular}

Sumber: Data Primer Tahun 2015

Tabel 3 Jenis alat kontrasepsi yang akan digunakan ibu hamil trimester III di Puskesmas Jetis Kota Yogyakarta mayoritas akan menggunkan KB suntik yaitu $44,4 \%$ atau 20 orang.

Tabel 4. Distribusi Frekuensi Tingkat Pengetahuan Ibu Hamil Trimester III Tentang KB Pasca Persalinan

\begin{tabular}{lcc}
\hline Tingkat Pengetahuan & $\mathbf{f}$ & $\mathbf{\%}$ \\
\hline Baik & 5 & 11,1 \\
Cukup & 23 & 51,1 \\
Kurang & 17 & 37,8 \\
Jumlah & 45 & 100 \\
\hline
\end{tabular}

Sumber: Data Primer Tahun 2015

Dilihat dari Tabel 4 distribusi frekuensi tingkat pengetahuan ibu hamil trimester III mayoritas $51,1 \%$ atau 23 orang ibu hamil berpengetahuan cukup.

Pengetahuan adalah hasil 'tahu', dan ini terjadi setelah orang melakukan pengindraan terhadap suatu objek tertentu. Pengindraan terjadi melalui pancaindra manusia, yakni: indra penglihatan, pendengaran, penciuman, rasa dan raba(9).

Pasca salin/masa nifas adalah masa yang dimulai setelah plasenta keluar (ari-ari) keluar dan berakhir ketika alat-alat kandungan kembali seperti keadaan semula (sebelum hamil). Masa nifas berlangsung selama kira-kira 6 minggu. Konseling mengenai $\mathrm{KB}$ diberikan pada saat kunjungan antenatal ke pelayanan kesehatan oleh bidan maupun dokter. Saat melakukan kunjungan antenatal ibu akan mendapatkan konseling KB, selain itu ibu juga mendapatkan konseling gizi, ASI ekslusif dan persiapan persalinan(5).

Kontrasepsi setelah persalinan merupakan inisiasi pemakaian metode kontrasepsi dalam waktu 6 minggu pertama setelah persalinan untuk mencegah kehamilan tidak diinginkan dan juga untuk mengatur jarak kehamilan. Pemilihan metode kontrasepsi pasca melahirkan perlu difikirkan dengan baik sehingga tidak mengganggu proses laktasi dan kesehatan bayinya(4).

Kontrasepsi setelah melahirkan dalan pelaksanaanya dikaitkan dengan program jampersal yang kini otomatis menjadi peserta BPJS dan perencanaan keluarga dimana wanita harus tahu bahwa dia bisa melahirkan segera setelah ia haid yang pertama, kesuburan wanita akan terus berlangsung sampai ia menopause. Wanita juga harus mengetahui kehamilan dan kelahiran berbaik adalah saat usia ibu 20-35 tahun. Persalinan pertama dan kedua paling baik jaraknya antara 2-4 tahun(10).

Tabel 5. Tabel Silang Responden Berdasarkan Umur, Pendidikan, Paritas, dengan Tingkat Pengetahuan

Tentang KB Pasca Persalinan di Puskesmas Jetis Kota Yogyakarta

\begin{tabular}{|c|c|c|c|c|c|c|c|c|}
\hline \multirow[t]{3}{*}{ karakteristik } & \multicolumn{6}{|c|}{$\begin{array}{c}\text { Tingkat Pengetahuan } \\
\text { Tentang KB Pasca } \\
\text { Persalinan }\end{array}$} & \multirow{2}{*}{\multicolumn{2}{|c|}{$\Sigma$}} \\
\hline & \multicolumn{2}{|c|}{ Baik } & \multicolumn{2}{|c|}{ Cukup } & \multicolumn{2}{|c|}{ Kurang } & & \\
\hline & $f$ & $\%$ & $f$ & $\%$ & $f$ & $\%$ & $f$ & $\%$ \\
\hline \multicolumn{9}{|l|}{ Umur } \\
\hline$<20$ & 0 & 0 & 0 & 0 & 0 & 0 & 0 & 0 \\
\hline $20-35$ & 3 & 8,6 & 17 & 48,6 & 15 & 42,9 & 35 & 100 \\
\hline$>35$ & 2 & 20 & 6 & 60 & 2 & 20 & 10 & 100 \\
\hline \multicolumn{9}{|l|}{ Pendidikan } \\
\hline $\begin{array}{l}\text { Tidak } \\
\text { Sekolah }\end{array}$ & 0 & 0 & 1 & 50 & 1 & 50 & 2 & 100 \\
\hline SD & 2 & 20 & 6 & 60 & 2 & 20 & 10 & 100 \\
\hline SMP & 1 & 14,3 & 3 & 42,9 & 3 & 42,9 & 7 & 100 \\
\hline SMA & 0 & 0 & 7 & 50 & 7 & 50 & 14 & 100 \\
\hline PT & 2 & 16,7 & 6 & 50 & 4 & 33,3 & 12 & 100 \\
\hline \multicolumn{9}{|l|}{ Paritas } \\
\hline Primipara & 1 & 5,3 & 9 & 47,4 & 9 & 47,4 & 19 & 100 \\
\hline Multipara & 4 & 15,4 & 14 & 53,8 & 8 & 30,8 & 26 & 100 \\
\hline $\begin{array}{l}\text { Grande } \\
\text { multipara }\end{array}$ & 0 & 0 & 0 & 0 & 0 & 0 & 0 & 100 \\
\hline Total & 5 & 11,1 & 23 & 51,1 & 17 & 37,8 & 45 & 100 \\
\hline
\end{tabular}

Sumber: Data Primer Tahun 2015 
Berdasarkan Tabel 5 didapat hasil berdasarkan umur persentase tingkat pengetahuan baik lebih tinggi pada responden dalam kelompok usia $>35$ tahun sedangkan persentase tingkat pengetahuan kurang lebih tinggi pada responden dalam kelompok usia 20-35 tahun. Umur sering dikaitkan dengan pengalaman. Pengalaman merupakan salah satu faktor yang dapat mempengaruhi pengetahuan yang berkaitan dengan umur dan pendidikan setiap orang, semakin bertambahnya umur dan pendidikan yang tinggi maka pengalaman dan pengetahuan seseorang semakin lebih luas(9).

Berdasarkan pendidikan persentase tingkat pengetahuan baik lebih tinggi pada responden berpendidikan SD, persentase tingkat pengetahuan kurang lebih tinggi pada responden yang tidak sekolah dan lulus SMA masing-masing yaitu 50\% (Tabel 5), hal ini dikarenakan pengetahuan tidak semata-mata didapat dari bangku sekolah melainkan dari informasi yang didapatkan seperti dari bidan, tetangga, keluarga dan teman. Pendidikan merupakan untuk memberikan pengetahuan sehingga terjadi perubahan perilaku positif yang meningkat. Semakin baik pengetahuan seseorang, maka umumnya perilakunya juga semakin baik(8).

Berdasarkan pendidikan persentase tingkat pengetahuan kurang lebih tinggi pada responden yang tidak sekolah yaitu $50 \%$. pendidikan seseorang berpengaruh pada pengetahuannya. Dengan demikian, semakin tinggi tingkat pendidikan seseorang maka akan semakin baik tingkat pengetahuannya. Begitupula sebaliknya semakin rendah tingkat pendidikan seseorang maka akan menghambat perkembangan sikapnya dalam menerima informasi sehingga pengetahuannya juga kurang(11). Berdasarkan pendidikan persentase tingkat pengetahuan yang kurang pada responden yang lulusan SMA yaitu $50 \%$. Hal ini dikarenakan ibu hamil trimester III yang lulusan SMA mayoritas adalah primigravida yaitu 10 orang $71,42 \%$.

Berdasarkan paritas persentase tingkat pengetahuan baik lebih tinggi pada responden multipara $(15,4 \%)$ hal ini karena multipara mempunyai anak lebih dari satu sehingga mereka mempunyai pengalaman dalam berKB dan persentase tingkat pengetahuan kurang lebih tinggi pada responden primigravida yaitu $(47,4 \%)$ hal ini karena mayoritas belum pernah menggunakan alat kontrasepsi. Paritas dapat mempengaruhi responden dalam menentukan pilihan menggunakan kontrasepsi(12). Pernyataan ini didukung dengan teori terdapat kencenderungan pengetahuan ibu yang berparitas tinggi lebih baik dari pengetahuan ibu yang berparitas rendah, karena mereka telah memperoleh pengalaman dan informasi(7).

Hasil penelitian menunjukan bahwa baik sebelum maupun setelah melahirkan nantinya, mayoritas ibu menggunakan jenis kontrasepsi suntik sebagai pilihan dalam menggunakan kontrasepsi. Sebelum kehamilan $42,2 \%$ ibu menggunakan KB suntik sebagai alat kontrasepsinya, sedangkan setelah melahirkan mayoritas ibu menggunakan suntik sebagai pilihan $44,4 \%$. Dalam persentase menunjukan peningkatan yang menggunakan alat kontrasepsi suntik sebagai pilihan utama dalam berKB. dikarenakan ibu menganggap KB suntik lebih sederhana dan lebih nyaman tidak rumit, ibu takut menggunakan IUD karena cerita di masyarakat ada yang gagal menggunakan IUD, ketika menstruasi darah lebih banyak dan cenderung lebih lama, bisa lari-lari di dalam perut, tidak nyaman saat berhubungan dan nyeri perut(13).

Hasil penelitian menunjukan bahwa sebagian besar ibu memiliki pengetahuan tentang KB pasca dalam katagori cukup sebanyak 23 orang atau $51,1 \%$. Baik, cukup dan kurangnya pengetahuan seseorang bisa dipengaruhi oleh latar belakang umur, pendidikan, pengalaman, paritas dan lingkungan dimana ia tinggal atau lingkungan yang dekat dengan aktifitasnya. Peran bidan dalam hal ini sangat dibutuhkan, terutama untuk memberi konseling mengenai alat kontrasepsi pasca persalinan(14). Pengetahuan adalah segala sesuatu yang ada dikepala kita. Kita dapat mengetahui sesuatu berdasarkan pengalaman yang kita miliki. Selain pengalaman, kita juga bisa tahu karena diberitahu orang lain(15).

\section{SIMPULAN DAN SARAN}

Berdasarkan Hasil Penelitian yang telah dilakukan kepada ibu hamil trimester III di Puskesmas Jetis Kota Yogyakarta dapat ditarik kesimpulan sebagian besar $(77,7 \%)$ responden berumur $20-35$ tahun, berpendidikan SMA (37,7\%) dan multipara $(57,8 \%)$. Tingkat pengetahuan ibu hamil trimester III tentang KB pasca persalinan di Puskesmas Jetis Kota Yogyakarta berdasarkan umur persentase tingkat pengetahuan baik mayoritas umur $>35$ tahun yaitu $20 \%$, berdasarkan paritas persentase paling tinggi multipara $57,8 \%$ dan berpendidikan SMA $17,7 \%$. Sebagian besar $44,4 \%$ ibu hamil trimester III di Puskesmas Jetis Kota Yogyakarta berencana menggunkan KB suntik setelah melahirkan nanti. Saran agar ibu hamil lebih meningkatkan lagi pengetahuan tentang KB pasca salin.

\section{RUJUKAN}

1. Handayani S. Buku Ajar Pelayanan Keluarga Berencana. Yogyakarta: Pustaka Rihama; 2010. 
2. Dinkes Kota Yogyakarta. Laporan Rekapitulasi PWS KB Tahun 2013. Yogyakarta: Dinas Kesehatan Kota Yogyakarta; 2014.

3. Maika A, Kuntohadi W. Analisis lanjut SDKI 2007: Penggunaan Alat Kontrasepsi Pasca Melahirkan. Jakarta: Puslitbang KB dan Kespro BKKBN; 2009.

4. Jamidi SK. Memilih Kontrasepsi Pasca Melahirkan [internet]. 2012 [cited 2014 November 12]. Available from: http://www.tanyadok.com.

5. Sulistyawati A. Asuhan Kehamilan Pada Masa Kehamilan. Jakarta: Salemba Medika; 2009.

6. Soekanto S. Sosiologi Suatu Pengantar. Jakarta: PT. Raja Grafika Persada; 2006.

7. Notoatmodjo S. Metodologi Penelitian Kesehatan. Jakarta: Rineka Cipta; 2010.

8. Machfoedz I. Metodologi Penelitian. Yogyakarta: Fitramaya; 2014.

9. Notoatmodjo S. Promosi Kesehatan dan IImu Perilaku. Jakarta: Rineka Cipta; 2007.

10. Affandi B. Strategi Peningkatan Pelayanan Kontrasepsi Jangka Panjang Pasca Persalinan dan Pasca Keguguran. Jakarta: Departemen Obstetri dan Ginekologi FKUI; 2011.

11. Nursalam, Pariani. Pendekatan Praktis Metodologi Riset Keperawatan. Jakarta: Sagung Seto; 2010.

12. Herlina, Suprji, Pratiwi. Gambaran Faktor yang Mempengaruhi Ibu Peserta Jampersal Dalam Penggunaan Alat Kontrasepsi Pasca Salin di Desa Kepuhrejo Kec. Takeran Kab. Magetah Tahun 2012. Penelitian Kesehatan Suara Forikes. 2012;III(3).

13. Kuswiranti Y. Tingkat Pengetahuan Ibu Hamil TM III Tentang KB Pasca Persalinan di Wilayah Kerja Puskesmas Gedang Sari I Gunung Kidul Tahun 2013. STIKES AIma Ata Yogyakarta; 2013.

14. Mustholihah I. Hubungan Pengetahuan Ibu Hamil Tentang Kontrasepsi Metode Amenorea Laktasi (MAL) Dengan Sikap Ibu Hamil Terhadap MAL (Studi Pada Ibu Hamil Trimester III di RB Citra Insani) Tahun 2012. Universitas Muhamadiyah Semarang; 2012.

15. Prasetya B. Metodologi Penelitian Kuantitatif. Jakarta: PT. Raja Grafindo Persada; 2007. 